\title{
The immune complex CTA1-DD/lgG adjuvant specifically targets connective tissue mast cells through Fc $\gamma$ RIIIA and augments anti-HPV immunity after nasal immunization
}

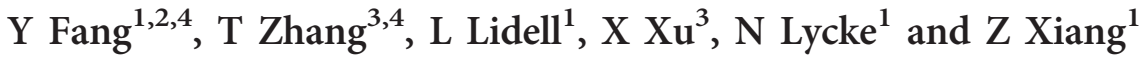

We have previously reported that CTA1-DD/lgG immune complexes augment antibody responses in a mast celldependent manner following intranasal (IN) immunizations. However, from a safety perspective, mast cell activation could preclude clinical use. Therefore, we have extended these studies and demonstrate that CTA1-DD/lgG immune complexes administered IN did not trigger an anaphylactic reaction. Importantly, CTA1-DD/lgE immune complexes did not activate mast cells. Interestingly, only connective tissue, but not mucosal, mast cells could be activated by CTA1-DD/ IgG immune complexes. This effect was mediated by FcyRIIIA, only expressed on connective tissue mast cells, and found in the nasal submucosa. Fc $\gamma$ RIIIA-deficient mice had compromised responses to immunization adjuvanted by CTA1-DD/IgG. Proof-of-concept studies revealed that IN immunized mice with human papillomavirus (HPV) type 16 L1 virus-like particles (VLP) and CTA1-DD/lgG immune complexes demonstrated strong and sustained specific antibody titers in serum and vaginal secretions. From a mast cell perspective, CTA1-DD/lgG immune complexes appear to be safe and effective mucosal adjuvants.

\section{INTRODUCTION}

As most pathogens gain access to the body through the mucosal membranes, stimulation of mucosal immunity is an attractive strategy to prevent not only local infections but also systemic infections. ${ }^{1}$ The advantages of mucosal vaccination are several fold, including needle-free administration, reducing the risk of cross-contamination, and increased compliance, and it does not require highly trained health-care providers. However, the most critical advantage of mucosal immunization is the stimulation of secretory IgA antibodies, which cannot be achieved by parenteral immunization. ${ }^{1,2}$ Successful mucosal immunization requires a strong adjuvant, not only to augment immunogenicity, but also to avoid tolerance induction, a protective phenomenon to avoid untoward reactions to the multitude of antigens, e.g., food antigens, encountered at mucosal membranes. ${ }^{1}$ Adjuvants are traditionally defined as substances, chemical compounds, or macromolecules that are used to augment immunogenicity of the vaccine, primarily by stimulating innate immunity through pattern recognition receptors, such as the Toll-like receptors (TLRs). ${ }^{3,4}$ Only a limited number of adjuvants have been approved for clinical use and no mucosal adjuvant is commercially available today. Hence, there is a need to develop effective mucosal adjuvants if nonliving mucosal vaccines are to be successfully launched. ${ }^{5}$ The most potent experimental adjuvants we know of are cholera toxin (CT) and the related heat-labile enterotoxin from Escherichia coli. ${ }^{6,7}$ Unfortunately, these adjuvants cannot be used in the clinic because of their toxicity, but many laboratories have developed less toxic, but potent, adjuvants by mutating the enzymatically active A1-A2 subunits of the holotoxin.

\footnotetext{
${ }^{1}$ Department of Microbiology and Immunology, Mucosal Immunobiology and Vaccine Research Center, Institute of Biomedicine, University of Gothenburg, Gothenburg, Sweden. ${ }^{2}$ Department of Microbiology and Immunology, Affiliated Hospital of Guiyang Medical College, Guiyang, China and ${ }^{3}$ Department of Biophysics and Structural Biology, Institute of Basic Medical Sciences, Chinese Academy of Medical Sciences, School of Basic Medicine, Peking Union Medical College, Beijing, China. Correspondence: X Xu (xuemeixu@vip.sina.com) or Z Xiang (zou.xiang@gu.se)

${ }^{4}$ The first two authors contributed equally to this work.
} 
A breakthrough in mast cell research was established by McLachlan $e$ e $a l .{ }^{8}$ who discovered that appropriately stimulated mast cells could act as natural enhancers of adaptive immune responses and, hence, could be exploited by adjuvant formulations for augmenting the immunogenicity of vaccines. It was demonstrated that mast cell activators, such as compound 48/80, triggered degranulation and strongly enhanced antibody responses, mainly through the release of tumor necrosis factor- $\alpha$ (TNF- $\alpha$ ), which promoted dendritic cell (DC) and T-cell functions. Given the strong effects on adaptive immune responses, it was proposed that some mast cell activators could be considered adjuvants and included in vaccines. ${ }^{8}$ For example, compound $48 / 80$ was shown to be effective in enhancing immune responses as seen after intradermal vaccination in mice with Bacillus anthracis antigens and following intranasal (IN) vaccination in rabbits with botulinum neurotoxin immunogens. ${ }^{9,10}$

We have developed a mucosal adjuvant, CTA1-DD, which is a fusion protein composed of CTA1, the A1 fragment of cholera toxin, and $\mathrm{DD}$, the two immunoglobulin-binding $\mathrm{D}$ regions of staphylococcal protein A. This rationally designed molecule is capable of circumventing the toxicity problem of CT holotoxin and targeting B cells. ${ }^{11}$ In multiple studies, we have shown that CTA1-DD is as potent as CT and that it is safe and nontoxic and, hence, could be considered an interesting clinically relevant mucosal vaccine adjuvant. ${ }^{12-14}$ The DD dimer, derived from Staphylococcus aureus protein A, was selected for its binding properties to immunoglobulin, in particular immunoglobulin $G(\operatorname{IgG}){ }^{15}$ In a recent study we exploited this property to bind IgG with the knowledge that mast cells could be targeted for immune enhancing functions. ${ }^{16}$ We reported that following IN immunization, CTA1-DD/IgG immune complexes activated resident mast cells and exerted augmenting effects on specific antibody responses. ${ }^{16} \mathrm{We}$ could prove that the augmenting function of CTA1-DD/IgG was mast cell dependent as we failed to observe a similar augmenting effect in mast cell-deficient mice. ${ }^{16}$

In this study we have further characterized the mechanisms of immune enhancement mediated by CTA1-DD/IgG and mast cell activation. We also evaluated the safety profile of such an adjuvant formulation with regard to the likelihood of provoking anaphylaxis. Finally, we tested the mast celldependent augmenting effect of CTA1-DD/IgG on antibody responses following IN immunizations in mice with the human papillomavirus (HPV) vaccine.

\section{RESULTS \\ CTA1-DD/lgG complexes do not elicit anaphylactic reactions}

Previously, we demonstrated that CTA1-DD/IgG complexes could activate mast cells and enhance antibody responses following IN immunizations. ${ }^{16}$ As mast cell degranulation is normally associated with allergic reactions, it could be argued that using CTA1-DD/IgG complexes could carry a high risk of eliciting anaphylactic responses. ${ }^{17}$ Therefore, we inoculated CTA1-DD/IgG complexes either IN or intravenously (IV) and monitored body temperature, routinely used as a measure of systemic hypersensitivity. ${ }^{18,19}$ As seen in Figure 1a,b, only a transient drop in body temperature was observed after administration of CTA1-DD/IgG, whereas, for comparison, specific IgE complexed with antigen (2,4-Dinitrophenol (DNP)) elicited a dramatic drop in body temperature (Figure 1c), reflecting an IgE-mediated anaphylactic response. However, CTA1-DD can bind immunoglobulins of all classes, including IgE, via the DD dimer. ${ }^{15}$ Because it is well known that multivalent allergens can bind $\operatorname{IgE}$ and elicit hypersensitivity reactions, we analyzed if CTA1-DD bound to IgE could activate mast cells through the high-affinity $\operatorname{IgE}$ receptor (FcERI) and increase the risk of a systemic anaphylactic reaction. To this end, we sensitized mast cells with IgE specific for DNP and added to the cultures of either DNPhuman serum albumin (DNP-HSA) or CTA1-DD. However, we failed to detect CTA1-DD-induced degranulation of mast cells, as measured by $\beta$-hexosaminidase release (Figure 1d) or TNF- $\alpha$ production (Figure 1e). In contrast, DNP-HSA strongly elicited degranulation and release of TNF- $\alpha$ from mast cells (Figure 1d,e). Furthermore, intradermal injections of CTA1DD into the skin of ears previously injected with anti-DNP IgE did not elicit anaphylactic reactions as measured by extravasation of the Evans blue dye, whereas DNP-HSA effectively triggered local extravasation of the dye because of degranulation of mast cells (Figure 1f). It is noteworthy that ears injected with CTA1-DD/IgG demonstrated enhanced dye extravasation compared with ears that were injected with IgG only (Figure 1f). Such dye extravasation into the local tissue has previously been confirmed to be mast cell dependent and reflect the degranulation of mast cells. ${ }^{20,21}$ Nevertheless, these results indicated that CTA1-DD/IgG complexes given IN did not evoke a local atopic or systemic anaphylactic reaction, supporting that this adjuvant strategy is safe to use.

\section{Phenotyping connective tissue-type and mucosal-type mast cells}

Bone marrow-derived cultured mast cells are commonly used to study mast cell biology in vitro. However, these cells, cultured in a standard interleukin-3 (IL-3)-enriched medium, do not respond to stimulation by IgG immune complexes, ${ }^{22,23}$ and hence not to CTA1-DD/IgG (data not shown). Tissue mast cells are a heterogeneous population, which, at least in mice, can be divided into connective tissue mast cells (CTMCs) and mucosal mast cells (MMCs). ${ }^{24}$ Bone marrow-derived cultured mast cells in IL-3-enriched medium resemble MMCs, which do not express Fc $\gamma$ RIIIA. ${ }^{22,25}$ Therefore, we predicted that CTMCs were most likely the target population for CTA1-DD/IgG immune complexes, as these cells are reported to express Fc $\gamma$ RIIIA. ${ }^{22,25}$ Accordingly, we cultured CTMCs and MMCs in medium enriched with different cytokines. ${ }^{26}$ Distinct granule patterns of CTMCs and MMCs were revealed by electron microscopy (Figure 2a). CTMCs demonstrated smaller granules of uniform sizes whereas MMCs had larger granules of variable sizes (Figure 2a), which is consistent with the descriptions regarding granular patterns of tissue 

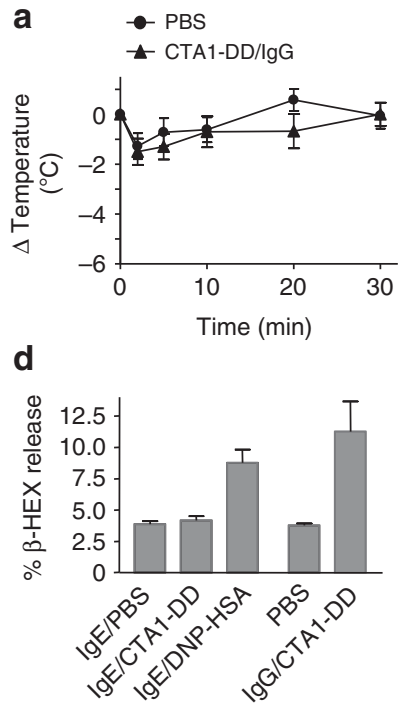

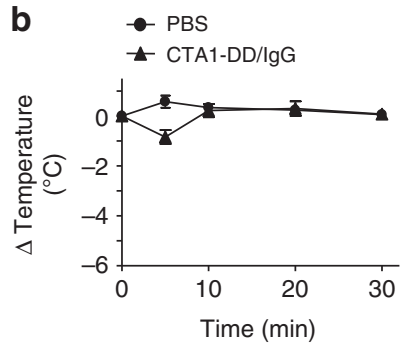

e

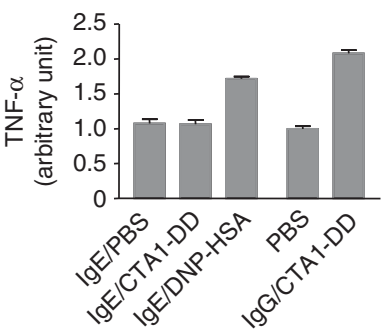

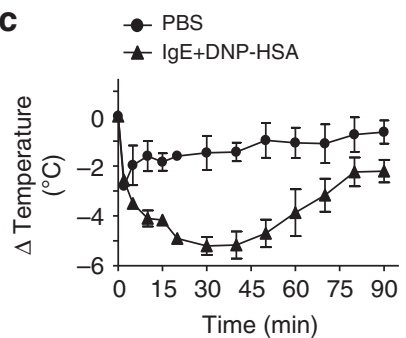

$\mathbf{f}$

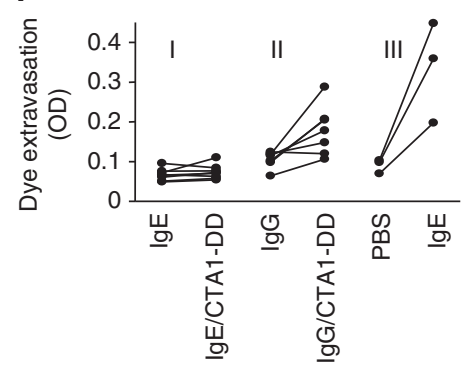

Figure 1 Comparison of mast cell activation and mouse anaphylaxis induced by immunoglobulin $\mathrm{G}(\lg \mathrm{G})$ and immunoglobulin $\mathrm{E}$ (IgE) immune complexes. (a-c) The changes in rectal temperatures of C57BL/6 mice over time after various types of challenge are shown. (a) Mice were anesthetized and intranasally (IN) administered with $20 \mu \mathrm{l}$ of phosphate-buffered saline (PBS) alone (circle) or PBS containing $5 \mu \mathrm{g}$ of CTA1-DD (a fusion protein composed of CTA1, the A1 fragment of cholera toxin, and DD, the two immunoglobulin-binding D regions of staphylococcal protein A) mixed with $20 \mu \mathrm{g} \mathrm{IgG}$ (triangle). (b) Mice were injected intravenously (IV) with $0.2 \mathrm{ml}$ of PBS alone (circle) or PBS containing $10 \mu \mathrm{g}$ of CTA1-DD mixed with $40 \mu \mathrm{g}$ IgG (triangle). (c) Mice were IV injected with $20 \mu \mathrm{g} \mathrm{IgE} \mathrm{against} \mathrm{2,4-Dinitrophenol} \mathrm{(DNP)} \mathrm{in} 0.2 \mathrm{ml}$ PBS followed $24 \mathrm{~h}$ later by an IV injection of $0.2 \mathrm{ml}$ of PBS (circle) or $100 \mu \mathrm{g}$ DNP-human serum albumin (DNP-HSA; triangle). (d, e) C57 cells were incubated with monoclonal IgE that is specific for DNP, washed, resuspended, and challenged with PBS, CTA1-DD, or DNP-HSA. In some experiments, cells were treated with PBS or IgG/CTA1-DD complexes. (d) Cell degranulation and (e) tumor necrosis factor- $\alpha$ (TNF- $\alpha$ ) protein were measured. $\beta$-Hex, $\beta$-hexosaminidase. (f) Three groups of C57BL/6 mice were analyzed for passive cutaneous anaphylaxis (PCA) assay. Mouse ears were injected with reagents as indicated followed by IV injection of Evans blue (groups I and II) or Evans blue together with DNP-HSA (Group III). Dye extravasation into the ear was measured. Each line represents one individual mouse. OD, optical density. Data are presented as mean \pm s.e.m. of (a) 8 mice or (b) 5 mice or (c) 3 mice, or (d, e) mean \pm s.e.m. of 5 separate experiments.

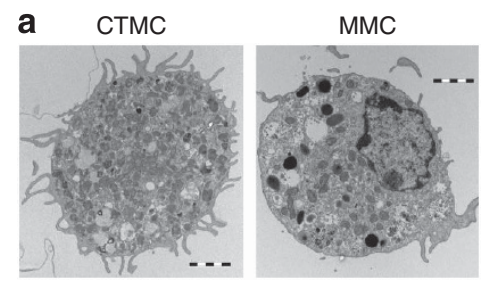

d

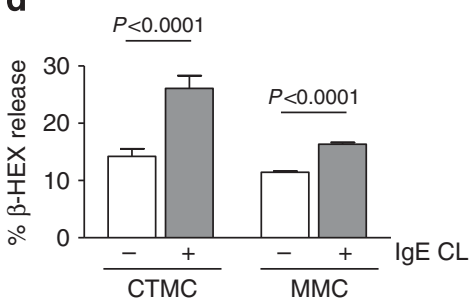

b

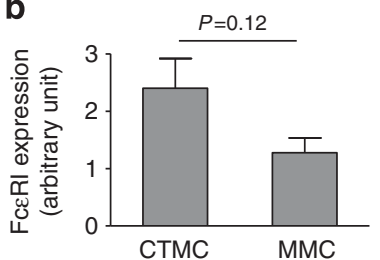

e $\mathrm{mMCP}-1$

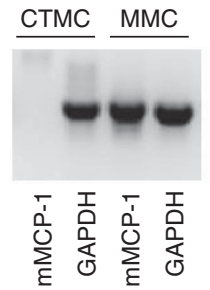

C

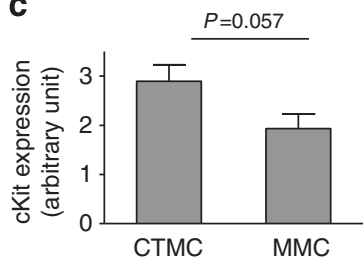

mMCP-5

$\sum_{0}^{O} \sum_{\sum}^{O}$

Figure 2 Phenotyping of connective tissue mast cell (CTMC) and mucosal mast cell (MMC) cultures. (a) CTMC and MMC granules were revealed by transmission electron microscopy. Scale bar $=2 \mu \mathrm{m}$. (b, c) Surface expression of (b) FceRl and (c) cKit was measured by flow cytometry and normalized values of geometric mean fluorescence were plotted. (d) CTMCs and MMCs were activated by immunoglobulin E (IgE) receptor crosslinking (IgE CL) and measured as explained in Figure 1d. Data represent mean \pm s.e.m. of $(\mathbf{b}, \mathbf{c})$ six or (d) three separate cell cultures. $\beta$-Hex, $\beta$-hexosaminidase. (e) mRNA expression of mouse mast cell proteases 1 and 5 (mMCP-1 and mMCP-5) was examined by reverse transcriptase-PCR (RT-PCR). Glyceraldehyde-3-phosphate dehydrogenase (GAPDH) was used as a loading/mRNA integrity control. Complementary DNAs (cDNAs) from two separate cultures were tested and one representative result is shown.

CTMCs and MMCs. ${ }^{27,28}$ Furthermore, these cultured CTMCs demonstrated a trend for expressing higher levels of FcERI and cKit expression (Figure 2b,c). Both CTMCs and
MMCs responded to IgE-mediated degranulation, although the former exhibited a greater potential than the latter (Figure 2d). MMCs expressed both mouse mast cell proteases 1 and 5 
(mMCP-1 and mMCP-5). In contrast, CTMCs expressed only mMCP-5 (Figure 2e). ${ }^{26}$

\section{CTA1-DD/lgG immune complexes target CTMCs through the Fc $\gamma$ RIIIA}

Next, we analyzed to which target cells CTA1-DD/IgG could bind. Indeed, only CTMCs, but not MMCs, expressed Fc $\gamma$ RIIIA, and CTA1-DD/IgG could interact with only the former cells (Figure 3a-c). Interestingly, we previously demonstrated that the mast cell line C57 responded to treatment with CTA1-DD/IgG and this cell line also expressed Fc $\gamma$ RIIIA and bound CTA1-DD/IgG (Figure 3a,d). ${ }^{16}$ Indeed, the C57 mast cell line is characterized to resemble CTMCs. ${ }^{29}$ Importantly, CTMCs cultured from Fc $\gamma$ RIIIA $^{-1-}$ mice could not bind CTA1-DD/IgG (Figure 3e). The binding of CTA1$\mathrm{DD} / \mathrm{IgG}$ to CTMCs and C57 mast cells was blocked by addition of antibody against Fc $\gamma$ RIIIA (Figure $3 \mathbf{b}$,d). In contrast, MMCs that lacked a significant expression of Fc $\gamma$ RIIIA failed to bind CTA1-DD/IgG complexes (Figure 3c).

The binding of CTA1-DD/IgG to CTMCs resulted in TNF- $\alpha$ and IL-6 mRNA production, which was not observed in MMCs (Figure 4a,b). Next, we tested the ability of mouse peritoneal mast cells, resembling CTMCs, ${ }^{28}$ for their responsiveness to CTA1-DD/IgG complexes and found that, indeed, these cells expressed Fc $\gamma$ RIIIA and bound CTA1-DD/IgG complexes (Figure 5a,b). As a consequence, they upregulated TNF- $\alpha$ mRNA expression and enhanced TNF- $\alpha$ production (Figure 5c,d). Thus, CTA1-DD/IgG complexes effectively targeted CTMCs through Fc $\gamma$ RIIIA, but did not interact with MMCs, and hence only CTMCs could be activated to produce TNF- $\alpha$ and to enhance adaptive immune responses in vivo.

Most importantly, mice either deficient in Fc $\gamma$ RIIIA or following treatment with chondroitin sulfate, a CTMC inhibitor, ${ }^{30}$ demonstrated substantially compromised antigen-specific immune responses following IN immunization with NP-CGG ((4-hydroxy-3-nitrophenyl) acetyl-36 coupled to chicken gammaglobulin) adjuvanted by CTA1-DD admixed to IgG (Figure 6), confirming the important roles of Fc $\gamma$ RIIIA and CTMCs in CTA1-DD/IgG-mediated adjuvanticity.

\section{Distribution of CTMCs in the nasal mucosa}

Given that CTA1-DD/IgG boosted antibody responses after IN immunization in a mast cell-dependent manner, ${ }^{16}$ and that only CTMCs responded to stimulation by CTA1-DD/IgG immune complexes, we next analyzed whether CTMCs were present in the nasal mucosa. We used toluidine blue, commonly used to stain metachromatic granules in both CTMCs and MMCs, and safranin, exclusively staining $\mathrm{CTMCs}^{31}$ to investigate the distribution of these mast cell subsets in nasal
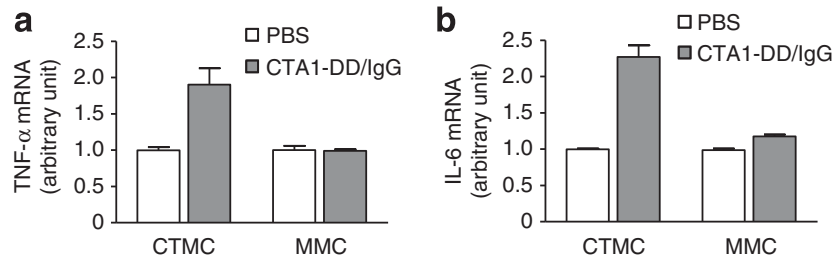

Figure 4 Cytokine transcript induction by mast cells. Connective tissue mast cells (CTMCs) and mucosal mast cells (MMCs) were treated with either phosphate-buffered saline (PBS) or CTA1-DD/lgG complexes. Relative mRNA expressions of (a) tumor necrosis factor- $\alpha$ (TNF- $\alpha$ ) and (b) interleukin-6 (IL-6) were evaluated by quantitative real-time PCR analysis. All PCR data shown are relative to HPRT and the mean values of the respective controls are normalized to 1 . Data represent the mean \pm range of two separate experiments. CTA1-DD, a fusion protein composed of CTA1, the A1 fragment of cholera toxin, and DD, the two immunoglobulin-binding $D$ regions of staphylococcal protein A; HPRT, hypoxanthine phosphoribosyltransferase; IgG, immunoglobulin G.
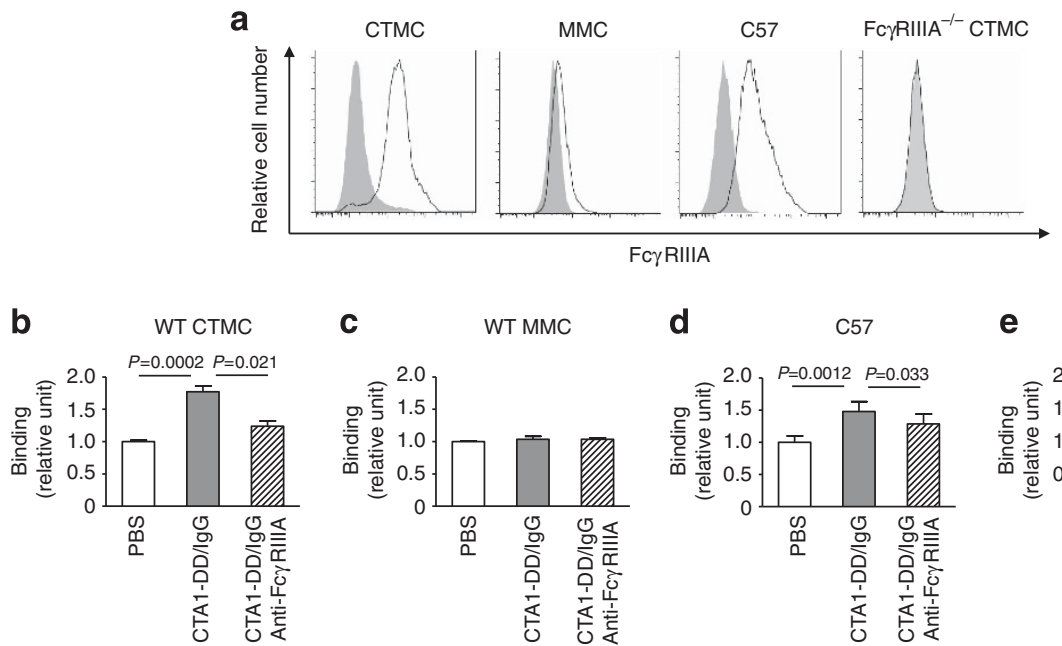

e $\quad \mathrm{FC \gamma RIIIA}^{-1-}$ CTMC

Figure 3 Expression of Fc $\gamma$ RIIIA and binding of CTA1-DD/lgG complexes by mast cells. (a) Cell surface expression of Fc $\gamma$ RIIIA in various mast cell cultures as indicated was measured by flow cytometry. Solid, isotype control; line, anti-Fc $\gamma$ RIIIA staining. (b-e) Binding of the CTA1-DD/lgG complexes to various types of cells in the presence or absence of Fc $\gamma$ RIIIA blocking was measured by flow cytometry. The geometric mean of the fluorescence intensities are plotted and the mean values of the respective controls are normalized to 1. Data represent (a) three separate experiments or the mean \pm s.e.m. of $(\mathbf{b}, \mathbf{c}, \mathbf{e})$ three or $(\mathbf{d})$ six separate experiments. CTA1-DD, a fusion protein composed of CTA1, the A1 fragment of cholera toxin, and DD, the two immunoglobulin-binding D regions of staphylococcal protein A; CTMC, connective tissue mast cell; IgG, immunoglobulin G; MMC, mucosal mast cell; PBS, phosphate-buffered saline; WT, wild type. 
a
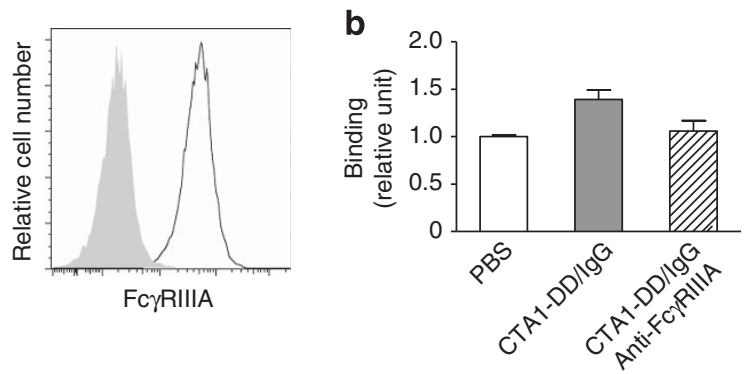

C
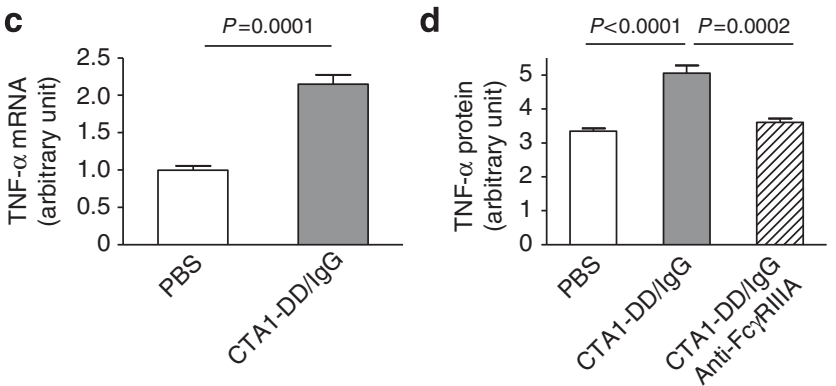

Figure 5 Expression of Fc $\gamma$ RIIIA by peritoneal cavity-derived cultured mast cells and their response to CTA1-DD/lgG immune complex stimulation. (a) Cell surface expression of $F c \gamma R$ IIIIA was measured as explained in Figure 3a. (b) Binding of the CTA1-DD and IgG immune complexes was measured as explained in Figure $3 \mathbf{b}-\mathbf{e}$. (c) Relative mRNA expression of tumor necrosis factor- $\alpha($ TNF- $\alpha$ ) was measured as explained in Figure 4a. (d) TNF- $\alpha$ protein production was measured by intracellular flow cytometry analysis. The geometric mean of the fluorescence intensities are plotted. Data represent mean \pm range of (b) two separate experiments or the mean \pm s.e.m. of (c) four separate experiments or (d) six separate experiments. CTA1-DD, a fusion protein composed of CTA1, the A1 fragment of cholera toxin, and DD, the two immunoglobulin-binding $D$ regions of staphylococcal protein $A ;$ IgG, immunoglobulin G; PBS, phosphate-buffered saline.
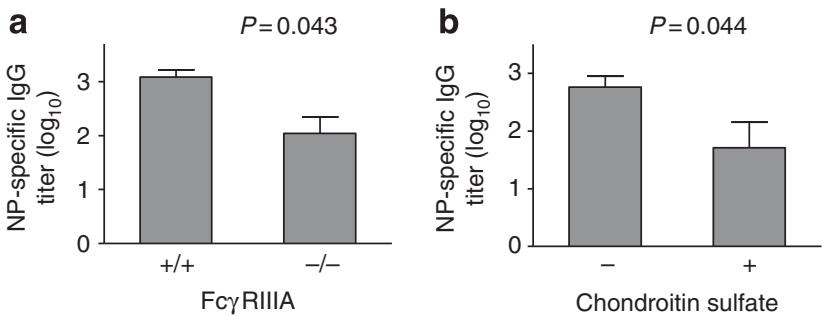

Figure 6 Decreased antigen-specific immunity in Fc $\gamma$ RIIIA-deficient mice or mice that have been treated with chondroitin sulfate. Mice were immunized intranasally twice with NP-CGG admixed to adjuvant complexes containing $5 \mu \mathrm{g}$ CTA1-DD (a fusion protein composed of CTA1, the $A 1$ fragment of cholera toxin, and DD, the two immunoglobulin-binding $D$ regions of staphylococcal protein $A$ ) and $20 \mu \mathrm{g}$ immunoglobulin $\mathrm{G}(\lg G)$ on days 0 and 10 . Blood was collected on day 20 , and serum NP-specific IgG antibody levels were analyzed by enzyme-linked immunosorbent assay (ELISA). (a) C57BL/6 mice of either Fc $\gamma$ RIIIA $+/+$ or $-/-$ genotypes were analyzed. (b) Wild-type C57BL/6 mice were administered intranasally with $20 \mu \mathrm{l} 10^{-4} \mathrm{M}$ chondroitin sulfate $30 \mathrm{~min}$ before each immunization. Data represent the mean \pm s.e.m. of (a) 5 mice or (b) 12-13 mice in each group. NP-CGG, (4-hydroxy-3-nitrophenyl) acetyl-36 coupled to chicken gammaglobulin.

mucosa. First, we confirmed these staining patterns using cultured MMCs and CTMCs (Figure 7a-d). Also, C57 cells were stained by both dyes documenting a connective tissue phenotype (Figure 7e,f). ${ }^{29}$ Cross-sectioning of the mouse nasal cavity demonstrated safranin-positive CTMCs only in the submucosa (Figure $7 \mathbf{h}$ ). In contrast, MMCs negative for safranin but positively stained with toluidine blue were found in the mucosa, adjacent to the epithelial cells (Figure $7 \mathbf{g}$ ). To document the selectivity of the staining, neither toluidine bluepositive nor safranin-positive cells were observed on nasal tissue sections from mast cell-deficient $\mathrm{Kit}^{w-s h / w-s h}$ mice (Figure $7 \mathbf{i}, \mathbf{j}$ ). These findings suggested that the mast cells targeted by CTA1-DD/IgG resided in the submucosa rather than the layer closest to the epithelial membrane.

To confirm that nasal mast cells expressed Fc $\gamma$ RIIIA, especially by tissue-resident CTMCs, we collected mucosal tissues from the mouse snout (Figure 8a) that were digested and single-cell suspensions were obtained. By flow cytometric analysis, these cells derived from nasal mucosal tissues contained a Gr-1 ${ }^{-} \mathrm{CD} 19^{-} \mathrm{CD}^{-}{ }^{-} \mathrm{cKit}^{+} \mathrm{IgE}^{+}$subpopulation (Figure 8b) that was absent in the tissues from the $\mathrm{Kit}^{\mathrm{w}-\mathrm{sh} / \mathrm{w}-\mathrm{sh}}$ mice (Figure 8e), confirming that this subpopulation was composed mainly of mast cells. These nasal mast cells could be further divided into two subgroups: one was positive and the other was negative for Fc $\gamma$ RIIIA (Figure 8c). Interestingly, the Fc $\gamma$ RIIIA-positive cells were also positive for TLR-2 (Figure 8c). This finding is consistent with a previous report documenting that only mature tissue CTMCs express TLR-2. ${ }^{32}$ Next, we sorted the Fc $\gamma$ RIIIA $^{+} /$TLR-2 ${ }^{+}$ population and these sorted cells could be stained with safranin (Figure 8d), a feature endowed by CTMCs. Taken together, these findings strongly support the presence of the Fc $\gamma$ RIIIAexpressing CTMCs in nasal mucosal tissues.

\section{The adjuvant effect of CTA1-DD/lgG in boosting HPV 16 L1 VLP vaccination}

By comparing wild-type and mast cell-deficient $K i t^{w-s h / w-s h}$ mice, we could establish that CTA1-DD/IgG complexes enhanced antibody production in a mast cell-dependent manner above that seen with CTA1-DD given IN alone. ${ }^{16}$ To further evaluate the adjuvant effect of this complex in a more infectious disease-relevant system, we immunized mice IN with the HPV monovalent vaccine type $16 \mathrm{~L} 1$ virus-like particles (VLP) in the presence of CTA1-DD/IgG complexes or CT holotoxin as a positive control adjuvant. We chose the pseudovirus neutralization assay as our primary evaluation tool that is recommended by the World Health Organization (WHO) as "the gold standard" for assessing the protective potential of HPV vaccines. ${ }^{33}$ The unadjuvanted HPV vaccine, given by the intramuscular route, is known to convey protective immunity, ${ }^{34}$ whereas we found it to be poorly immunogenic when given IN (Figure 9a). In contrast, CTA1-DD/IgG significantly enhanced specific antibody responses with high serum anti-HPV 16 neutralizing antibody titers even at 24 weeks following IN immunizations. This enhanced response was comparable to that generated with the $\mathrm{CT}$ adjuvant (Figure 9a,b). Furthermore, anti-HPV 16 neutralizing antibodies in the vaginal washings were readily detected and high levels were maintained at 24 weeks after the last 

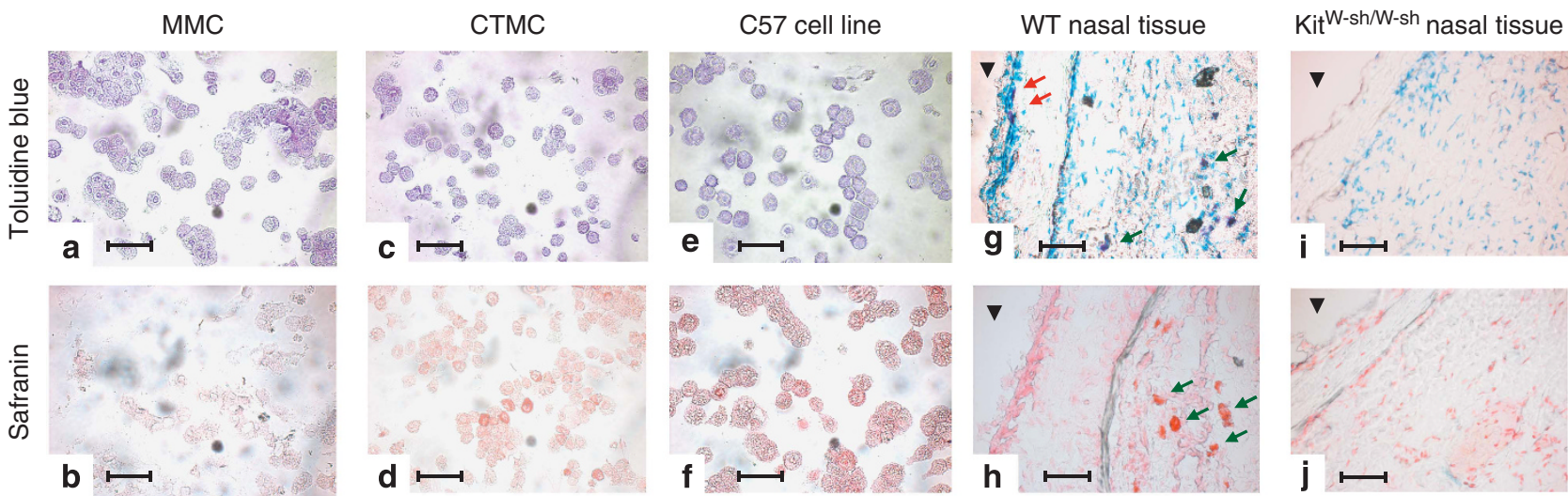

Figure 7 Mast cell phenotyping by microscopy. In vitro generated mucosal mast cells (MMCs) and connective tissue mast cells (CTMCs), the C57 cell line, and mouse nasal tissue sectioning from C57BL/6 (wild type (WT)) and C57BL/6-Kit ${ }^{W-s h / W-s h}$ mice were stained with toluidine blue that stains all mast cells $(\mathbf{a}, \mathbf{c}, \mathbf{e}, \mathbf{g}, \mathbf{i})$, and safranin that stains only CTMCs $(\mathbf{b}, \mathbf{d}, \mathbf{f}, \mathbf{h}, \mathbf{j})$. Arrowheads, nasal cavity; red arrows, tissue MMCs; green arrows, safranin-positive tissue CTMCs. Scale bar $=50 \mu \mathrm{m}$.
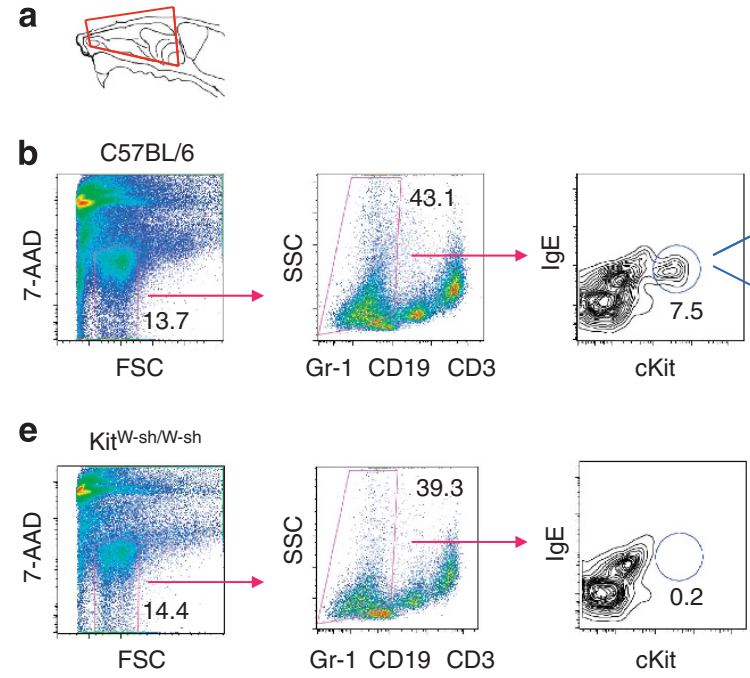

C

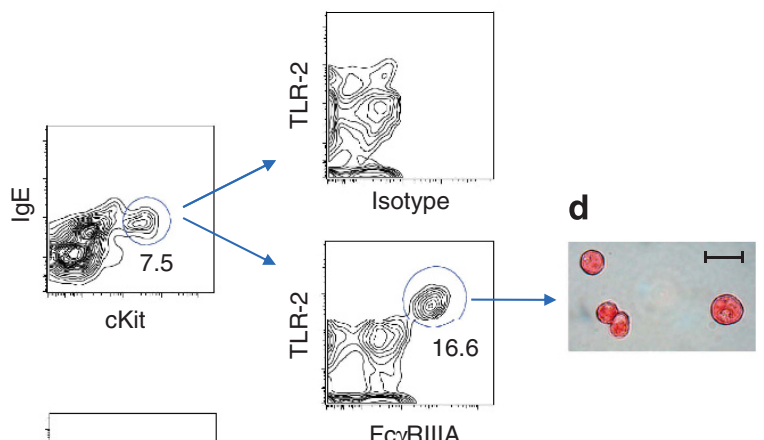

FcyRIIIA

Figure 8 Expression of Fc $\gamma$ RIIIIA by mouse nasal mast cells. (a) The box indicates the part of a skinless mouse snout from which mucosal tissues were obtained. (b) Gating strategy for $\mathrm{cKit}^{+} \mathrm{IgE}^{+}$mast cells among $\mathrm{Gr}^{-} \mathrm{CD}^{-} 9^{-} \mathrm{CD}^{-}$cells from a C57BL/6 mouse. 7-AAD,

7-aminoactinomycin D; FSC, forward scatter; IgG, immunoglobulin G; SSC, side scatter. (c) Expression of Fc $\gamma$ RIIIA and Toll-like receptor 2 (TLR-2) by nasal mast cells, assessed after gating on the $\mathrm{cKit}^{+} \mathrm{IgE}^{+}$population. (d) The Fc $\gamma \mathrm{RIIIA}{ }^{+} / \mathrm{TLR}-2^{+}$population was sorted and stained by safranin. Scale bar $=20 \mu \mathrm{m}$. (e) Nasal tissues were obtained from a C57BL/6-Kit ${ }^{W-s h} / W$-sh mouse and analyzed as in $\mathbf{b}$ demonstrating the lack of $\mathrm{cKit}^{+}$

$\mathrm{IgE}^{+}$mast cells. Data are representative of three separate experiments. Numbers in or adjacent to outlined areas indicate percent cells in each gate.

immunization (Figure 9c,d). Thus, CTA1-DD/IgG complexes greatly enhanced the effect of an IN immunization with the human HPV monovalent 16 VLP vaccine. We also measured the HPV 16-specific IgA responses in the vaginal washings by enzyme-linked immunosorbent assay (ELISA). Substantial levels of specific IgA were observed 8 weeks after the immunizations facilitated by CTA1-DD/IgG, which seemed to demonstrate a trend toward better performance of CTA1$\mathrm{DD} / \mathrm{IgG}$ than the CT holotoxin $(P=0.059$; Figure 9e). However, the titers in the groups of both CTA1-DD/IgG and CT dropped almost to background levels at 24 weeks (Figure 9f), a time point when the mucosal neutralizing capacity was at least partially maintained (Figure 9d). These findings suggest that immunoglobulins other than $\operatorname{IgA}$, e.g., IgG, may also contribute to the mucosal defense against HPV.

\section{DISCUSSION}

Mast cells are classically defined as innate immune effector cells mainly associated with unwanted hypersensitivity reactions and IgE-mediated allergic inflammation. However, recent discoveries have also pointed to other biologically relevant functions, such as those linked to immune protection and resistance against infections. ${ }^{35,36}$ More specifically, the finding that mast cell activation could directly influence adaptive immune responses through the release of TNF- $\alpha$ and other mediators that could enhance immune responses is 

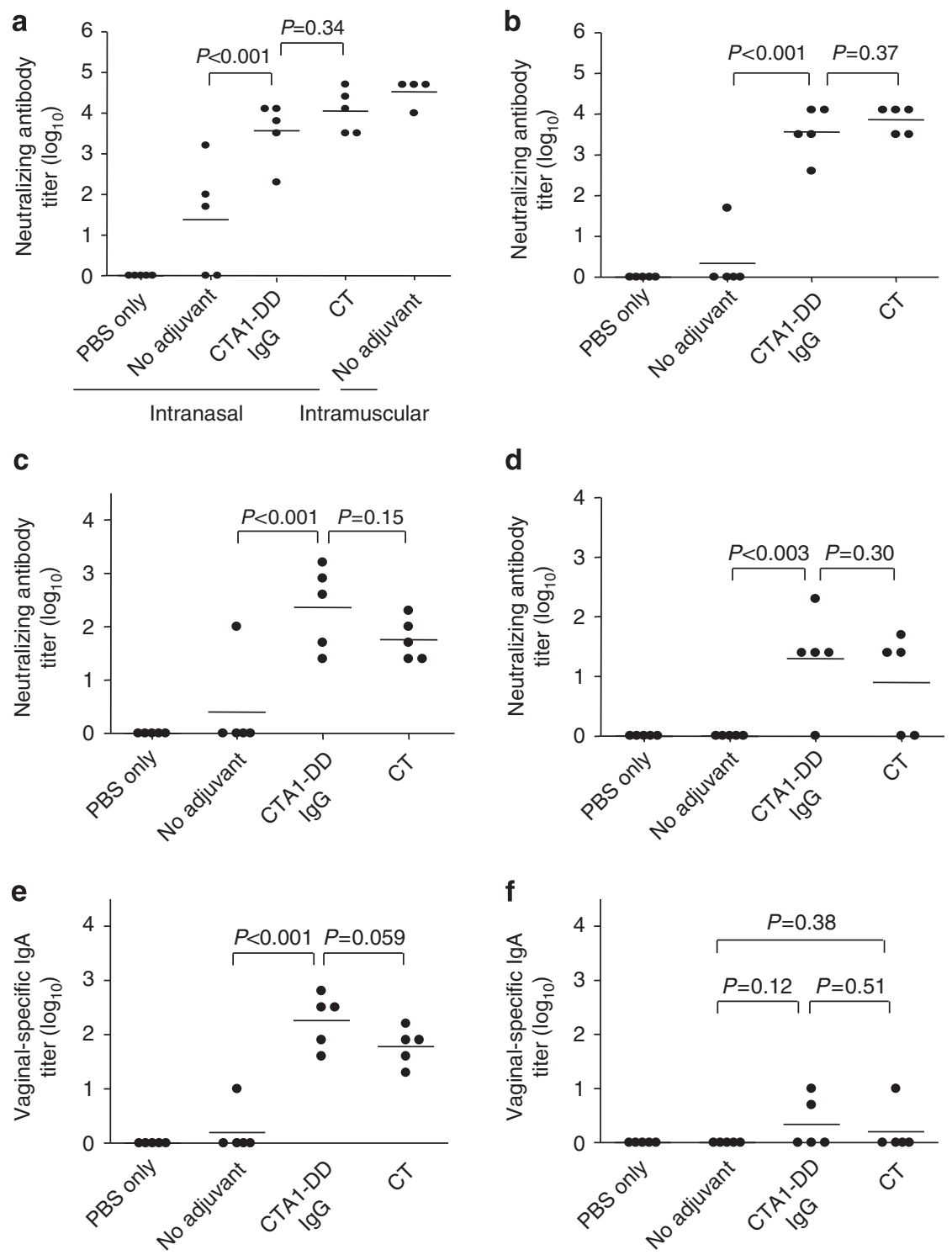

Figure 9 Neutralizing antibody and vaginal immunoglobulin A (IgA) responses to human papillomavirus (HPV) 16 vaccination. BALB/c mice were immunized with the HPV type 16 vaccine together with or without adjuvant preparations as indicated at 0,2 , and 4 weeks. The mice were all immunized intranasally except one group in a that had intramuscular injection. (a-d) The neutralizing antibody titers in the (a, b) serum and (c, $\mathbf{d})$ vaginal washings were detected (a) 2 weeks, (c) 8 weeks, or (b, d) 24 weeks after the third immunization by the pseudovirus neutralization assay. (e, f) The HPV 16 L1 virus-like particle (VLP)-specific IgA titers in the vaginal washings were detected (e) 8 weeks or (f) 24 weeks after the third immunization by VLP-based enzyme-linked immunosorbent assay (ELISA). The antibody titers were calculated from $\log _{10}$-transformed values. Each dot represents data from an individual mouse and bars indicate the average values. CT, cholera toxin; CTA1-DD, a fusion protein composed of CTA1, the A1 fragment of cholera toxin, and DD, the two immunoglobulin-binding D regions of staphylococcal protein A; IgG, immunoglobulin G; PBS, phosphate-buffered saline.

interesting. ${ }^{8}$ Hence, these findings provide a major shift in the paradigm of mast cell functions and argue that mast cells should not always be thought of in the context of IgE-mediated pathology. Evidence is accumulating that mast cells may have multifaceted roles in orchestrating immune responses, which could be exploited in, for example, designing more effective vaccine adjuvants. ${ }^{35,37,38}$ Here we show that this may be especially true for mucosal adjuvants and IN immunizations.

Mast cells are strategically located to the host-environment interface and have been shown to be critical for an optimal immune defense against some pathogens by virtue of their ability to produce proinflammatory mediators. ${ }^{35}$ Hence, mast cells can mobilize inflammatory cells at the site of infection and facilitate the maturation and migration of DCs to draining lymph nodes, in part through the release of TNF- $\alpha .{ }^{39-42}$ In fact, mast cells and DCs share territorial space, which could be particularly important for resistance against infectious agents at mucosal membranes. ${ }^{37}$ In this respect, both mast cells and DCs form the first line of defense against invading pathogens.

Previously, we demonstrated that the combination of CTA1$\mathrm{DD}$ and IgG could enhance adaptive immune responses by 
activating mast cells. ${ }^{16}$ In this study we demonstrate that only CTMCs carrying the Fc $\gamma$ RIIIA were targeted by CTA1-DD/IgG immune complexes and that this resulted in the upregulation of mRNA expression of TNF- $\alpha$ and IL- 6 and the release of TNF- $\alpha$. Mast cell-dependent TNF- $\alpha$ release can drive DC maturation and migration to draining lymph nodes. ${ }^{8,39-42}$ Also, IL- 6 was found to be produced by CTA1-DD/IgG-exposed CTMCs and this may influence DC functions as well as directly promote $\mathrm{T}$ - and B-cell expansion and differentiation. ${ }^{43}$ This mast cell-dependent mechanism further augmented the adjuvant effect of CTA1DD following IN immunization with the human HPV vaccine and enhanced serum and genital tract anti-HPV antibody titers.

On the basis of tissue location, histochemical staining, content of proteases, and functionality, two major subtypes of rodent mast cells have been described, i.e., CTMCs and MMCs. ${ }^{24}$ In this study we demonstrated that bone marrow cells cultured in conditioned medium could be driven into the CTMC lineage. These cells, but not MMCs, expressed the Fc $\gamma$ RIIIA (Figure 3a), which is consistent with previous observations. ${ }^{44}$ We found that CTMCs, indeed, bound CTA1$\mathrm{DD} / \mathrm{IgG}$ and responded with upregulation of cytokine mRNA transcripts (Figures 3 and 4). However, the terms CTMCs and MMCs were originally coined when murine mast cells from a limited number of tissues were analyzed and the terms were only relatively correlated with the tissue distribution. ${ }^{24}$ The $\mathrm{MC}_{\mathrm{TC}}$ and $\mathrm{MC}_{\mathrm{T}}$, the human counterparts of murine CTMCs and MMCs, respectively, have even poorer correlation with the tissues where they reside. Therefore, the so-called "connective tissue" mast cells are also present at least in some, if not all, mucosal tissues. Here, we observed the distribution of CTMCs in mouse nasal submucosa (Figures 7 and 8). Similarly, CTMCs were also identified in the mouse gastric submucosa. ${ }^{31}$ Of note, C48/80, which is shown as an effective adjuvant following IN immunizations, ${ }^{8,10}$ selectively activates CTMCs but not MMCs ${ }^{26,45,46}$ and, hence, it has to penetrate "deep" into the submucosa to reach the CTMCs. Furthermore, differential responsiveness of CTMCs and MMCs to other stimuli has also been described. For example, TLR ligands selectively activate CTMCs, but not MMCs, resulting in the release of cytokines including IL-6 and TNF. ${ }^{32,47}$ These observations highlight an important role of CTMCs in mucosal defense against pathogens, but they also place emphasis on the fact that mast cells can bridge innate and adaptive immune responses.

In addition to FceRI, which is the high-affinity receptor for $\mathrm{IgE}$, mast cells express receptors for $\operatorname{IgG}$, or Fc $\gamma \mathrm{R}$, and respond to IgG-mediated activation. Four different classes of Fc $\gamma$ Rs, known as Fc $\gamma$ RI, Fc $\gamma$ RIIB, Fc $\gamma$ RIIIA, and Fc $\gamma$ RIV, have been identified in mice. Of these murine Fc $\gamma$ Rs, only Fc $\gamma$ RIIB and Fc $\gamma$ RIIIA are expressed by mast cells. Virtually all mouse mast cells express the inhibitory receptor Fc $\gamma$ RIIB, whereas only CTMCs express the activating receptor Fc $\gamma$ RIIIA. In contrast to FceRI that has a narrow expression spectrum (mainly mast cells and basophils in mice), Fc $\gamma$ RIIIA and Fc $\gamma$ RIIB are expressed by many other innate immune effector cells. At least FcyRIIIA is found to be expressed by natural killer cells, macrophages, basophils, neutrophils, and DCs, in addition to mast cells. ${ }^{48}$ The possible interaction of CTA1-DD/IgG complex with Fc $\gamma$ RIIIA on other cells awaits further characterization.

Immune complexes administered at the mucosal surfaces can be transported into the submucosa by a number of mechanisms. The most well-studied mechanism is the neonatal Fc receptor ( $\mathrm{FcRn}$ )-mediated transepithelial transport of IgG. ${ }^{49}$ Specifically, expression of $\mathrm{FcRn}$ in various locations within the respiratory epithelium has also been documented. ${ }^{50}$ Thus, CTA1-DD/IgG may be transported into the submucosa across epithelial barriers via the binding of IgG to FcRn. A number of strategies have been proposed to increase the efficiency of drug delivery across the mucosal barrier. Modification of the residues around the FcRn-Fc binding interface is one suggestion. ${ }^{49}$ Also, nasal administration of vaccines with the help of mucoadhesives results in enhanced penetration of the molecules across mucosal barriers. ${ }^{51}$ These strategies may be applied to further enhance the transport of the CTA1-DD/IgG complex into submucosa where CTMCs reside.

Given that CTA1-DD/IgG complexes augmented antibody responses in a mast cell-dependent manner following IN immunizations, we were concerned about the potential risks of activating mast cell-driven hypersensitivity reactions. However, we did not observe any inadvertent hypersensitivity reaction, neither local reactogenicity nor systemic anaphylactic reactions. Specifically, CTA1-DD/IgE complexes failed to activate mast cells, suggesting that there is no increased risk of provoking a severe hypersensitivity reaction upon IN administration of CTA1-DD, even to atopic individuals suffering from IgE-mediated allergies.

To our knowledge, this is the first study to demonstrate that a mucosal adjuvant, CTA1-DD/IgG, can activate CTMCs, which augmented specific antibody response following IN immunizations. Promising results with the human HPV vaccine was observed and IN immunizations stimulated strong serum and genital tract anti-HPV type 16 antibody responses following IN administration of CTA1-DD/IgG immune complexes and HPV-16 vaccine. HPVs are a large family of small doublestranded DNA viruses that often infect epithelia of mucosa and skin, causing benign and malignant lesions of epithelial tissues, such as genital warts and cervical cancers. HPV 16 is etiologically linked to $>50 \%$ of cervical cancers globally. ${ }^{52}$ It was earlier reported that mucosal immunization of HPV VLP can induce both local and systemic immune responses following vaginal, rectal, oral, nasal, or lower airway immunizations. ${ }^{53-57}$

In summary, our study has further elucidated our understanding of mast cell-mediated immune enhancement at mucosal membranes as well as demonstrated the safety profile of CTA1-DD/IgG immune complexes for IN immunizations. We found that CTMCs, but not MMCs, specifically were targeted through the Fc $\gamma$ RIIIA. These augmenting effects had a strong impact on enhancing anti-HPV antibody production as detected in both serum and genital tract secretions. We believe this work may have important implications for understanding mast cell-DC interactions at mucosal membranes in vivo as 
well as for the development of mucosal vaccine adjuvants that actively exploit the link between mast cells and DCs for improving mucosal vaccine functions.

\section{METHODS}

Mice and immunization. $\mathrm{C} 57 \mathrm{BL} / 6$ and $\mathrm{BALB} / \mathrm{c}$ mice were purchased from Taconic (Ry, Denmark) or the Institute of Laboratory Animal Science, Chinese Academy of Medical Sciences (Beijing, China). Fc $\gamma$ RIIIA ${ }^{-1-}$ mice were purchased from The Jackson Laboratory (Bar Harbor, ME). C57BL/6-Kit ${ }^{W-s h / W-s h}$ mice were provided by Professor Gunnar Nilsson (Karolinska Institute, Stockholm, Sweden). For immunization with the model antigen NP-CGG, C57BL/6 mice were immunized and analyzed as previously reported. ${ }^{17}$ In some of the immunizations where indicated, mice received $20 \mu \mathrm{l} 10^{-4} \mathrm{M}$ of chondroitin sulfate (Sigma-Aldrich, St Louis, MO) or an identical volume of phosphate-buffered saline (PBS) $30 \mathrm{~min}$ before the administration of antigen and adjuvant complexes. For immunization with the HPV vaccine, BALB/c mice were given $5 \mu \mathrm{g}$ of HPV $16 \mathrm{~L} 1$ VLPs three times at 2-week intervals either intranasally with $5 \mu \mathrm{g}$ of CTA1-DD plus $20 \mu \mathrm{g}$ IgG or $2 \mu \mathrm{g}$ of CT or intramuscularly without any adjuvant. After HPV immunization, serum samples were collected 2 weeks and 24 weeks after the final immunization. To minimize the influence of the mouse estrous cycle that may modify the induction of immune responses in the vaginal mucosa ${ }^{58,59}$ vaginal washings $(20 \mu \mathrm{l})$ were obtained daily for 5 consecutive days and combined for each individual mouse 8 and 24 weeks after the final immunization. All animal procedures were carried out with the approval of the Ethical Committee for Laboratory Animals in Gothenburg or the institutional animal care and use committee in Beijing.

Cell culture. The mouse mast cell line C57 was obtained from Professor Gunnar Nilsson (Karolinska Institute ) and was cultured at $37^{\circ} \mathrm{C}$ in $5 \% \mathrm{CO}_{2}$ in RPMI-1640 (Sigma-Aldrich) with $2 \mathrm{~mm}$ L-glutamine (Sigma-Aldrich), 10\% heat inactivated fetal calf serum (Fisher Scientific, Waltham, MA), $50 \mu \mathrm{m} \beta$-mercaptoethanol (SigmaAldrich), as well as $100 \mathrm{U} \mathrm{ml}^{-1}$ penicillin (Sigma-Aldrich) and $100 \mathrm{~g} \mathrm{ml}^{-1}$ streptomycin (Sigma-Aldrich). Bone marrow cells from C57BL/6 mice were cultured to differentiate into either MMCs or CTMCs using specific media as reported. ${ }^{26}$ Essentially, both types of mast cells were obtained by culturing mouse bone marrow cells for at least 3 weeks. MMCs were grown in Dulbecco's modified Eagle's medium (Sigma-Aldrich) containing IL-3 (5\% supernatant of X63/0 myeloma cells transfected with an IL-3 expression vector), $10 \%$ fetal calf serum, $2 \mathrm{~mm}$ L-glutamine, $1 \mathrm{~mm}$ sodium pyruvate, and regular amounts of penicillin and streptomycin, which was supplemented with $25 \mathrm{ng} \mathrm{ml}^{-1}$ recombinant murine stem cell factor (ImmunoTools, Friesoythe, Germany), $5 \mathrm{ng} \mathrm{ml}^{-1}$ recombinant murine IL-9 (ImmunoTools), and $1 \mathrm{ng} \mathrm{ml}^{-1}$ recombinant human TGF- $\beta 1$ (PeproTech, Rocky Hill, NJ). CTMCs were cultured in RPMI-1640 medium containing the same amounts of fetal calf serum, sodium pyruvate, penicillin, and streptomycin as for MMCs, plus $4 \mathrm{~mm}$ L-glutamine, $0.1 \mathrm{~mm}$ modified Eagle's medium nonessential amino acids, and $50 \mu \mathrm{m} \beta$-mercaptoethanol (Sigma-Aldrich), supplemented with $25 \mathrm{ng} \mathrm{ml}^{-1}$ recombinant murine stem cell factor (ImmunoTools) and $1 \mathrm{ng} \mathrm{ml}^{-1}$ recombinant murine IL-4 (ImmunoTools). In some experiments, mast cells were prepared and cultured from mouse peritoneal cavity as reported. ${ }^{60}$

Flow cytometry and mast cell phenotyping. Cell surface expression of cKit and FceRI were measured by flow cytometry using Alexa Flour 647-conjugated anti-mouse FceRI (Clone MAR-1; eBioscience, San Diego, CA) and phycoerythrin-conjugated anti-mouse cKit (Clone 2B8; eBioscience), respectively, to determine mast cell differentiation. For cells isolated from the nasal tissue, fluorescein isothiocyanate (FITC)-conjugated rat anti-mouse IgE (Clone R35-72; BD Biosciences, BD Pharmingen, San Diego, CA) was used to detect IgE that should be bound by FceRI. In all the measurements by flow cytometry, mast cells were gated as the Fc\&RI ${ }^{+} \mathrm{cKit}^{+}$or IgE $^{+} \mathrm{cKit}^{+}$population. For nasal tissue analysis, identification of mast cells was based on the $\mathrm{CD}^{-}$ $\mathrm{CD}_{19}{ }^{-} \mathrm{Gr}_{-1}^{-}$population using BD Horizon V450 conjugated antiCD3 (Clone 17A2), anti-CD19 (Clone 1D3), and anti-Gr-1 (Clone RB6-8C5) antibodies (all from BD Biosciences). For the expression of mast cell proteases, $\mathrm{mMCP}-1$ and $\mathrm{mMCP}-5$ were measured by reverse transcriptase-PCR (RT-PCR) as reported. ${ }^{26}$ Expression of TLR-2 was measured by flow cytometry using an anti-human/mouse TLR-2 antibody (clone T2.5; eBioscience). Cell surface expression of Fc $\gamma$ RIIIA was measured with a FITC- or allophycocyanin-conjugated rat antimouse Fc $\gamma$ RIIIA (Clone 275003; R\&D Systems, Minneapolis, MN) compared with an isotype control antibody.

Microscopy. Cells from different cultures were stained with $0.5 \%$ toluidine blue (Sigma-Aldrich) to visualize mast cell granules. In some experiments, cells were stained with $0.1 \%$ safranin (Merck Millipore, Darmstadt, Germany) to identify CTMCs. Tissue sections revealing the nasal mucosa and submucosa from C57BL/6 mice were prepared as reported previously, ${ }^{16}$ and then stained with toluidine blue or safranin.

IgG immune complex binding. To determine the binding of CTA1DD/IgG complex through Fc $\gamma$ RIIIA, $10^{5}$ cells pretreated or not with $10 \mu \mathrm{g} \mathrm{ml}^{-1}$ anti-Fc $\gamma$ RIIIA at $4{ }^{\circ} \mathrm{C}$ for $10 \mathrm{~min}$ were incubated with $10 \mu \mathrm{g} \mathrm{ml}^{-1}$ CTA1-DD mixed with $40 \mu \mathrm{g} \mathrm{ml}^{-1}$ polyclonal mouse IgG at $4{ }^{\circ} \mathrm{C}$ for $1 \mathrm{~h}$. Next, the cells were washed extensively and stained with FITC-conjugated goat anti-mouse IgG/IgM (Polyclonal; BD Biosciences).

Mast cell activation and measurements. Cells were incubated in culture medium at a concentration of $10^{6}$ cells per $\mathrm{ml}$ with various stimuli. In some experiment, cells were stimulated with $10 \mu \mathrm{g} \mathrm{ml}^{-1}$ CTA1-DD mixed with $40 \mu \mathrm{g} \mathrm{ml}^{-1}$ polyclonal mouse IgG. Alternatively, cells were incubated with IgE that recognizes DNP (Clone SPE-7, Sigma-Aldrich) at a concentration of $1 \mu \mathrm{g} \mathrm{ml}^{-1}$ for $1 \mathrm{~h}$ and then washed, followed by the addition of either $10 \mu \mathrm{g} \mathrm{ml}^{-1}$ DNP-HSA (30-40 DNP molecules per HSA, Sigma-Aldrich) or $10 \mu \mathrm{g} \mathrm{ml}^{-1}$ CTA1-DD. Cells were then incubated for $30 \mathrm{~min}$ for $\beta$-hexosaminidase release as a measure of degranulation using an enzymatic colorimetric assay $^{61}$ or for $4 \mathrm{~h}$ for the measurement of intracellular TNF- $\alpha$ and IL-6 production and $2 \mathrm{~h}$ for mRNA expression as described. ${ }^{16}$ To detect mRNA transcripts of TNF- $\alpha$ and IL-6, reverse transcription real-time PCR was used as reported. ${ }^{16}$ The IL- 6 primer sequences were 5'-GCTACCAAACTGGATATAATCAGGA- ${ }^{\prime}$ and 5' ${ }^{\prime}$-CCAGGTAG CTATGGTACTCCAGAA- ${ }^{\prime}$ and the probe used was the Universal ProbeLibrary probe number 6 . TNF- $\alpha$ protein production was measured by intracellular flow cytometry as reported. ${ }^{16}$

For the in vivo mast cell activation, passive cutaneous anaphylaxis assay was used as a positive control as previously described. ${ }^{62}$ Essentially, anesthetized mice were injected intradermally with $10 \mu \mathrm{l}$ of PBS containing $0.4 \mu \mathrm{g}$ of IgE that recognizes DNP (Clone SPE-7; Sigma-Aldrich) in one ear and PBS in the other ear. The next day, mice were injected IV through the tail vein with $200 \mu \mathrm{l}$ of PBS containing $10 \mathrm{mg} \mathrm{ml}^{-1}$ Evans blue (Sigma-Aldrich) and $5 \mu \mathrm{g} \mathrm{ml}^{-1}$ of DNP-HSA. Mouse ears were removed $20 \mathrm{~min}$ after the Evans blue injection and the dye extravasation was quantified as previously described. ${ }^{16}$ To test if CTA1-DD could replace DNP-HSA, by virtue of its unspecific binding potential with immunoglobulins, in crosslinking the $\operatorname{IgE}$ bound to $\operatorname{IgE}$ receptors, i.e., FceRI, and thus activating mast cells, the abovementioned passive cutaneous anaphylaxis assay was modified. Mice received IgE sensitization on both ears, and the next day, $1 \mu \mathrm{g}$ of CTA1DD in $10 \mu \mathrm{l}$ of PBS was injected intradermally in one ear and PBS in the other. Mice were immediately injected IV with Evans blue as detailed above. Also, in contrast to IgE/CTA1-DD, the effect of IgG/CTA1-DD complexes on the dye extravasation was also tested as a positive control. The ears of these mice were injected with IgG on one side and IgG/CTA1-DD on the other, followed by an IV injection of Evans blue as explained above. 
Induction and measurement of systemic anaphylactic reaction. To establish standard mouse systemic anaphylactic responses, wild-type C57BL/6 mice were IV systemically sensitized with $20 \mu \mathrm{g}$ anti-DNP IgE (Clone SPE-7, Sigma-Aldrich) in $200 \mu \mathrm{l}$ PBS followed $24 \mathrm{~h}$ later by an IV injection of $100 \mu \mathrm{g}$ DNP-HSA. To investigate whether mice also developed systemic anaphylaxis as a result of IN administration of CTA1-DD/IgG, some mice received $20 \mu \mathrm{l}$ PBS containing $5 \mu \mathrm{g}$ of CTA1-DD mixed with $20 \mu \mathrm{g}$ polyclonal mouse IgG IN after being anesthetized with isoflurane. In some experiments, mice received $200 \mu \mathrm{l}$ PBS IV containing $10 \mu \mathrm{g}$ of CTA1-DD mixed with $40 \mu \mathrm{g}$ polyclonal mouse IgG. Rectal temperature was measured over time as a readout of the systemic anaphylactic reaction. The data are expressed as changes in temperature from baseline values. A digital thermometer with a probe for mice was used to measure rectal temperatures.

Electron microscopy. Cells were fixed with $2 \%$ paraformaldehyde and $2.5 \%$ glutaraldehyde in $0.05 \mathrm{M} \mathrm{Na}$ cacodylate buffer. Postfixation was performed with $1 \%$ osmium tetroxide and $1 \%$ potassium hexacyanoferrate. After en bloc staining with $0.5 \%$ uranylacetate, cells were dehydrated, pelleted, and embedded in epoxy resin according to routines. After curing, $\approx 50 \mathrm{~nm}$ sections were cut with a Leica UC6 ultramicrotome (Leica Microsystems, Vienna, Austria) fitted with a diamond knife. After contrasting with uranylacetate and lead citrate, sections were examined in a LEO 912AB Omega transmission electron microscope (Carl Zeiss, Oberkochen, Germany) equipped with an Olympic-SiS (Münster, Germany) Veleta CCD camera for digital imaging.

Preparation of single-cell suspension from mouse nasal tissues. Skins were carefully removed from the snout of C57BL/6 mice. Nasal tissues together with the turbinates were cut and minced by scissors. Single-cell suspensions were obtained by digestion with $400 \mathrm{U} \mathrm{ml}^{-1}$ DNase I (Roche) and $25 \mu \mathrm{g} \mathrm{ml}^{-1}$ Liberase TM (Roche) at $37^{\circ} \mathrm{C}$ for $20 \mathrm{~min}$. Single cells were obtained by passing the preparation through a $70-\mu \mathrm{m}$ cell strainer followed by red blood cell lysis.

Pseudovirus neutralization assay. HPV 16 pseudovirus neutralization assay was performed as reported previously. ${ }^{34}$ Essentially, HPV 16 protein-encoded pseudoviruses containing pEGFP-N1 reporting plasmid (Clontech, Mountain View, CA) were produced by 293TT cells (provided by Professor John Schiller). Pseudoviruses were efficiently purified from the cell lysates containing pseudoviruses by OptiPrep (iodixanol) density gradient ultracentrifugation and diluted appropriately to $2,000 \mathrm{TCID}_{50}$ (tissue culture infectious dose 50 ) per $50 \mu \mathrm{l}$. Mouse sera or vaginal washings were subjected to a twofold serial dilution and the sample of each dilution was mixed with an identical volume of pseudovirus preparation followed by incubation at $4{ }^{\circ} \mathrm{C}$ for $1 \mathrm{~h}$. The mixture was then added to the $293 \mathrm{TT}$ cell culture at $37^{\circ} \mathrm{C}$ for $72 \mathrm{~h}$. Pseudoviral infection was determined by flow cytometry measuring the proportion of fluorescent cells that had taken up the pEGFP-N1 plasmid that was correlated to the amount of viral particles. The percent infection inhibition was calculated by the infection rate of the group containing only the pseudovirus subtracted by the rate of pseudoviral infection neutralized by the antibody-containing samples. The end point titers were calculated as the highest sample dilution, yet still with percent infection inhibition $>50 \%$.

VLP-based ELISA. ELISA plates were coated with 100 ng HPV 16 L1 VLP in $100 \mu \mathrm{l}$ PBS per well, followed by incubation at $4{ }^{\circ} \mathrm{C}$ overnight. Plates were next blocked at room temperature for $2 \mathrm{~h}$. Vaginal washings were serially diluted and incubated in the wells for $2 \mathrm{~h}$ at room temperature. Wells were washed 3 times followed by incubation with horseradish peroxidase-conjugated rabbit-anti-mouse IgA (Biosynthesis Biotechnology, Beijing, China) in a dilution of 1:2,000. After five times of washing, o-rthophenylenediamine (Sigma) was added $\left(100 \mu \mathrm{l}\right.$ per well) followed by incubation for $5 \mathrm{~min}$ at $37^{\circ} \mathrm{C}$. The reaction was stopped by adding $50 \mu \mathrm{l}$ of $2 \mathrm{M} \mathrm{H}_{2} \mathrm{SO}_{4}$ per well. Plates were read using an automated ELISA microplate reader at $490 \mathrm{~nm}$. The end point titers were calculated as the base 10 logarithm of the highest sera dilution with an absorbance $>0.2$ and at least twice the background absorbance.

Statistical analysis. The HPV immunization data were analyzed by one-way analysis of variance using SPSS software (IBM, Armonk, NY). Values were compared between different groups. All the other data were analyzed for statistical significance by using either an unpaired or a paired $t$-test depending on the data type in GraphPad Prism software (La Jolla, CA).

\section{ACKNOWLEDGEMENTS}

We thank Xixiu Xie and Yanchun Liu for technical support, Dr Mats Bemark for assistance in cell sorting, and Professor Bengt Johansson for assistance in electron microscopy. We also thank Professor John T. Schiller (National Cancer Institute, Bethesda, MD ) for providing the 293TT cell line and p16SHELL plasmid. This work was supported by grants from the Mucosal Immunobiology and Vaccine Research Center (MIVAC), University of Gothenburg; Stiftelsen Clas Groschinskys Minnesfond; Wilhelm och Martina Lundgrens Vetenskapsfond; Kungl. Vetenskapsoch Vitterhets-Forskningsansökan Samhället Göteborg (KVVS); Beijing Natural Science Foundation (no. 7102110); and National Natural Science Foundation of China (no. 31070813).

\section{DISCLOSURE}

The authors declared no conflict of interest.

c) 2013 Society for Mucosal Immunology

\section{REFERENCES}

1. Lycke, N. Recent progress in mucosal vaccine development: potential and limitations. Nat. Rev. Immunol. 12, 592-605 (2012).

2. Brandtzaeg, P. Induction of secretory immunity and memory at mucosal surfaces. Vaccine 25, 5467-5484 (2007).

3. Guy, B. The perfect mix: recent progress in adjuvant research. Nat. Rev. Microbiol. 5, 505-517 (2007)

4. McKee, A.S., Munks, M.W. \& Marrack, P. How do adjuvants work? Important considerations for new generation adjuvants. Immunity 27 , 687-690 (2007)

5. Lambrecht, B.N., Kool, M., Willart, M.A. \& Hammad, H. Mechanism of action of clinically approved adjuvants. Curr. Opin. Immunol. 21, 23-29 (2009).

6. van Ginkel, F.W. et al. Enterotoxin-based mucosal adjuvants alter antigen trafficking and induce inflammatory responses in the nasal tract. Infect. Immun. 73, 6892-6902 (2005).

7. Svennerholm, A.M. From cholera to enterotoxigenic Escherichia coli (ETEC) vaccine development. Indian J. Med. Res. 133, 188-196 (2011).

8. McLachlan, J.B. et al. Mast cell activators: a new class of highly effective vaccine adjuvants. Nat. Med. 14, 536-541 (2008).

9. McGowen, A.L., Hale, L.P., Shelburne, C.P., Abraham, S.N. \& Staats, H.F. The mast cell activator compound $48 / 80$ is safe and effective when used as an adjuvant for intradermal immunization with Bacillus anthracis protective antigen. Vaccine 27, 3544-3552 (2009).

10. Staats, H.F. et al. Mucosal targeting of a BoNT/A subunit vaccine adjuvanted with a mast cell activator enhances induction of BoNT/A neutralizing antibodies in rabbits. PLoS One 6, e16532 (2011).

11. Agren, L.C., Ekman, L., Lowenadler, B., Nedrud, J.G. \& Lycke, N.Y. Adjuvanticity of the cholera toxin A1-based gene fusion protein, CTA1-DD, is critically dependent on the ADP-ribosyltransferase and Ig-binding activity. J. Immunol. 162, 2432-2440 (1999).

12. Lycke, N. \& Bemark, M. Mucosal adjuvants and long-term memory development with special focus on CTA1-DD and other ADP-ribosylating toxins. Mucosal Immunol. 3, 556-566 (2010).

13. Bemark, M. et al. A unique role of the cholera toxin A1-DD adjuvant for long-term plasma and memory B cell development. J. Immunol. 186, 1399-1410 (2011).

14. Mattsson, J. et al. Complement activation and complement receptors on follicular dendritic cells are critical for the function of a targeted adjuvant. J. Immunol. 187, 3641-3652 (2011). 
15. Agren, L.C., Ekman, L., Lowenadler, B. \& Lycke, N.Y. Genetically engineered nontoxic vaccine adjuvant that combines $B$ cell targeting with immunomodulation by cholera toxin A1 subunit. J. Immunol. 158, 3936-3946 (1997).

16. Fang, Y., Larsson, L., Mattsson, J., Lycke, N. \& Xiang, Z. Mast cells contribute to the mucosal adjuvant effect of CTA1-DD after IgG-complex formation. J. Immunol. 185, 2935-2941 (2010).

17. Brown, J.M., Wilson, T.M. \& Metcalfe, D.D. The mast cell and allergic diseases: role in pathogenesis and implications for therapy. Clin. Exp. Allergy 38, 4-18 (2008).

18. Tsujimura, Y. et al. Basophils play a pivotal role in immunoglobulin-Gmediated but not immunoglobulin-E-mediated systemic anaphylaxis. Immunity 28, 581-589 (2008).

19. Ujike, A. et al. Modulation of immunoglobulin (Ig)E-mediated systemic anaphylaxis by low-affinity Fc receptors for IgG. J. Exp. Med. 189 1573-1579 (1999).

20. Ovary, Z. Passive cutaneous anaphylaxis in the mouse. J. Immunol. 81, 355-357 (1958).

21. Braga, F. \& Mota, I. Homologous passive cutaneous anaphylaxis (PCA) in mice and heterologous PCA induced in rats with mouse IgE. Immunology 30, 655-669 (1976).

22. Malbec, O. \& Daeron, M. The mast cell lgG receptors and their roles in tissue inflammation. Immunol. Rev. 217, 206-221 (2007).

23. Hiraoka, S. et al. Fc receptor beta subunit is required for full activation of mast cells through Fc receptor engagement. Int. Immunol. 11, 199-207 (1999).

24. Moon, T.C. et al. Advances in mast cell biology: new understanding of heterogeneity and function. Mucosal Immunol. 3, 111-128 (2010).

25. Latour, S., Bonnerot, C., Fridman, W.H. \& Daeron, M. Induction of tumor necrosis factor-alpha production by mast cells via Fc gamma R. Role of the FC gamma RIII gamma subunit. J. Immunol. 149, 2155-2162 (1992).

26. Ekoff, M., Strasser, A. \& Nilsson, G. FcepsilonRI aggregation promotes survival of connective tissue-like mast cells but not mucosal-like mast cells. J. Immunol. 178, 4177-4183 (2007).

27. Welle, M. Development, significance, and heterogeneity of mast cells with particular regard to the mast cell-specific proteases chymase and tryptase. J. Leukoc. Biol. 61, 233-245 (1997).

28. Kitamura, Y. Heterogeneity of mast cells and phenotypic change between subpopulations. Annu. Rev. Immunol. 7, 59-76 (1989).

29. Young, J.D., Liu, C.C., Butler, G., Cohn, Z.A. \& Galli, S.J. Identification, purification, and characterization of a mast cell-associated cytolytic factor related to tumor necrosis factor. Proc. Natl. Acad. Sci. USA 84, 9175-9179 (1987).

30. Theoharides, T.C. et al. Chondroitin sulphate inhibits connective tissue mast cells. Br. J. Pharmacol. 131, 1039-1049 (2000).

31. Gersch, C. et al. Mast cells and macrophages in normal C57/BL/6 mice. Histochem. Cell Biol. 118, 41-49 (2002).

32. Mrabet-Dahbi, S., Metz, M., Dudeck, A., Zuberbier, T. \& Maurer, M. Murine mast cells secrete a unique profile of cytokines and prostaglandins in response to distinct TLR2 ligands. Exp. Dermatol. 18, 437-444 (2009).

33. Dessy, F.J. et al. Correlation between direct ELISA, single epitope-based inhibition ELISA and pseudovirion-based neutralization assay for measuring anti-HPV-16 and anti-HPV-18 antibody response after vaccination with the AS04-adjuvanted HPV-16/18 cervical cancer vaccine. Hum. Vaccin. 4, 425-434 (2008).

34. Zhang, T. et al. Trivalent Human Papillomavirus (HPV) VLP vaccine covering HPV type 58 can elicit high level of humoral immunity but also induce immune interference among component types. Vaccine 28, 3479-3487 (2010).

35. Abraham, S.N. \& St John, A.L. Mast cell-orchestrated immunity to pathogens. Nat. Rev. Immunol. 10, 440-452 (2010).

36. Galli, S.J. \& Tsai, M. Mast cells in allergy and infection: versatile effector and regulatory cells in innate and adaptive immunity. Eur. J. Immunol. 40, 1843-1851 (2010)

37. Galli, S.J., Nakae, S. \& Tsai, M. Mast cells in the development of adaptive immune responses. Nat. Immunol. 6, 135-142 (2005).

38. Galli, S.J., Grimbaldeston, M. \& Tsai, M. Immunomodulatory mast cells: negative, as well as positive, regulators of immunity. Nat. Rev. Immunol. $\mathbf{8}$, 478-486 (2008)

39. Jawdat, D.M., Rowden, G. \& Marshall, J.S. Mast cells have a pivotal role in TNF-independent lymph node hypertrophy and the mobilization of
Langerhans cells in response to bacterial peptidoglycan. J. Immunol. 177, 1755-1762 (2006).

40. Suto, $\mathrm{H}$. et al. Mast cell-associated TNF promotes dendritic cell migration. J. Immunol. 176, 4102-4112 (2006).

41. Heib, V. et al. Mast cells are crucial for early inflammation, migration of Langerhans cells, and CTL responses following topical application of TLR7 ligand in mice. Blood 110, 946-953 (2007).

42. Shelburne, C.P. et al. Mast cells augment adaptive immunity by orchestrating dendritic cell trafficking through infected tissues. Cell Host Microbe 6, 331-342 (2009).

43. Dawicki, W., Jawdat, D.W., Xu, N. \& Marshall, J.S. Mast cells, histamine, and IL-6 regulate the selective influx of dendritic cell subsets into an inflamed lymph node. J. Immunol. 184, 2116-2123 (2010).

44. Lobell, R.B., Arm, J.P., Raizman, M.B., Austen, K.F. \& Katz, H.R. Intracellular degradation of $F_{C}$ gamma RIII in mouse bone marrow culture-derived progenitor mast cells prevents its surface expression and associated function. J. Biol. Chem. 268, 1207-1212 (1993).

45. Stanovnik, L., Logonder-Mlinsek, M. \& Erjavec, F. The effect of compound $48 / 80$ and of electrical field stimulation on mast cells in the isolated mouse stomach. Agents Actions 23, 300-303 (1988).

46. Enerback, L. \& Lowhagen, G.B. Long term increase of mucosal mast cells in the rat induced by administration of compound 48/80. Cell Tissue Res. 198, 209-215 (1979).

47. Matsushima, H., Yamada, N., Matsue, H. \& Shimada, S. TLR3-, TLR7-, and TLR9-mediated production of proinflammatory cytokines and chemokines from murine connective tissue type skin-derived mast cells but not from bone marrow-derived mast cells. J. Immunol. 173, 531-541 (2004).

48. Nimmerjahn, F. \& Ravetch, J.V. Fcgamma receptors as regulators of immune responses. Nat. Rev. Immunol. 8, 34-47 (2008).

49. Roopenian, D.C. \& Akilesh, S. FCRn: the neonatal Fc receptor comes of age. Nat. Rev. Immunol. 7, 715-725 (2007).

50. Bitonti, A.J. \& Dumont, J.A. Pulmonary administration of therapeutic proteins using an immunoglobulin transport pathway. Adv. Drug Deliv. Rev. 58, 1106-1118 (2006).

51. Ugwoke, M.l., Agu, R.U., Verbeke, N. \& Kinget, R. Nasal mucoadhesive drug delivery: background, applications, trends and future perspectives. Adv. Drug Deliv. Rev. 57, 1640-1665 (2005).

52. WHO/ICO Information Centre on HPV and Cervical Cancer. HPV and cervical cancer in the 2007 report. Vaccine 25 (Suppl 3), C1-230 (2007).

53. Revaz, V. et al. Humoral and cellular immune responses to airway immunization of mice with human papillomavirus type 16 virus-like particles and mucosal adjuvants. Antiviral Res. 76, 75-85 (2007).

54. Sasagawa, T. et al. A human papillomavirus type 16 vaccine by oral delivery of L1 protein. Virus Res. 110, 81-90 (2005).

55. Nardelli-Haefliger, D. et al. Immune responses induced by lower airway mucosal immunisation with a human papillomavirus type 16 virus-like particle vaccine. Vaccine 23, 3634-3641 (2005).

56. Nardelli-Haefliger, D. et al. Mucosal but not parenteral immunization with purified human papillomavirus type 16 virus-like particles induces neutralizing titers of antibodies throughout the estrous cycle of mice. J. Virol. 73, 9609-9613 (1999).

57. Hunter, Z., Tumban, E., Dziduszko, A. \& Chackerian, B. Aerosol delivery of virus-like particles to the genital tract induces local and systemic antibody responses. Vaccine 29, 4584-4592 (2011).

58. Wira, C., Fahey, J., Wallace, P. \& Yeaman, G. Effect of the menstrual cycle on immunological parameters in the human female reproductive tract. $J$. Acquir. Immune Defic. Syndr. 38 (Suppl 1), S34-S36 (2005).

59. Kaushic, C., Ashkar, A.A., Reid, L.A. \& Rosenthal, K.L. Progesterone increases susceptibility and decreases immune responses to genital herpes infection. J. Virol. 77, 4558-4565 (2003).

60. Dudeck, A., Suender, C.A., Kostka, S.L., von Stebut, E. \& Maurer, M. Mast cells promote Th1 and Th17 responses by modulating dendritic cell maturation and function. Eur. J. Immunol. 41, 1883-1893 (2011).

61. Xiang, Z. \& Nilsson, G. IgE receptor-mediated release of nerve growth factor by mast cells. Clin. Exp. Allergy 30, 1379-1386 (2000).

62. Xiang, Z., Moller, C. \& Nilsson, G. Readministration of IgE is required for repeated passive cutaneous anaphylaxis in mice. Int. Arch. Allergy Immunol. 141, 168-171 (2006). 